\title{
Political Integration and Reconstruction of Chongqing Rural Society in Early Years of Establishment of the Nation
}

\author{
Xiuru Li \\ Chongqing University of Science and Technology, Chongqing, 410031, China
}

\begin{abstract}
Key words: Early years of establishment of the nation, Chongqing, Rural society, Political
\end{abstract} integration, Reconstruction

\begin{abstract}
In the early years of establishment of the nation, both social environment and peasants' living environment were complex. In the face of severe development situation, Chongqing rural area conformed to the call of Chinese Communist Party (CCP) and established political integration and reconstruction mechanism for rural society so as to meet social demand for new China construction. This not just promoted rural order, but also eradicated traditional neighborhood administrative system during taking over old regime. Meanwhile, complete rural land right was established and improved. During restoring political factor, cultural factor, and economic factor in the structure of rural society in Chongqing, political participation enthusiasm of rural peasants was mobilized to the largest extent. This paper intensively interprets social necessity and specific implementation strategy of political integration and reconstruction of Chongqing rural society in the early years of establishment of the nation, and discusses the political function of political integration and reconstruction so as to clearly deconstruct political integration and reconstruction framework of Chongqing rural society and offer reference.
\end{abstract}

\section{Social necessity of political integration and reconstruction of Chongqing rural society in the early years of establishment of the nation}

\section{Social necessity of CCP nature and historical responsibility}

CCP is a proletarian party which was established under the guidance of Marxism and also the loyal guardian of Chinese people. After the establishment of China, social environment gradually tended to be stable. To better reflect social noumenon of Chinese nation - people and better serve people, reconstruction of political structure and social order is an obligatory responsibility. In this period, CCP not just gradually integrated leadership and basic core, but also gave a full play of a leading role and deeply implemented reconstruction of rural social force.

\section{Social necessity of conforming to development situation of China}

In the early years of establishment of the nation, we were faced with just stable domestic environment and very severe foreign situation. Some western imperialism forces implemented economic blockade and other malicious acts. All these affected China's political and economic structure. Besides, Chongqing rural people's regime was just established and needed to overall take over old regime. In comprehensive view of various adverse factors and turmoil situation, political integration and reconstruction of Chongqing rural society well conformed to era development trend. Social stability could be really ensured only through establishing dynamic improvement mechanism and measures.

\section{Realistic necessity of meeting the primary task - China's social development}

In the early years of establishment of the nation, numerous things waited to be done. Emancipating and developing the productive forces should serve as the basic goal. Besides, national economy should be recovered and developed gradually in practical production. Effective measures should be taken to further facilitate agricultural development. However, new China had a large population, and the agricultural acreage was small. In addition, economic structure fell behind. Agricultural 
production framework and agricultural output needed to be surveyed again. Thus, Chongqing local government should upgrade cultivation mode and technical framework, and actively create economic operation structure beneficial to peasants' development during promoting land system change. To meet China's development, it was required to drive Chongqing rural society to carry out political integration and reconstruction so as to establish a stable political and social environment.

\section{Necessity of meeting peasants' survival ideal and overcoming their limitation}

For peasants, their fundamental wish is to gain economic benefit beneficial to survival during breaking through their development limitation. In this process, it is necessary to improve peasants; social status so as to achieve the development goal of a moderately prosperous society. In the early years of establishment of the nation, to achieve peasants' ideal, China provided a sound political development platform which not just met peasants' political participation enthusiasm, but also created political participation opportunity for them during gaining land. But, due to peasants' quality and family concept, antiquate ideological structure was deep. To eradicate such ideological limitation, political integration and reconstruction of Chongqing rural society became an inevitable social development trend. Social development requirements can only conform only through improving education and quality ${ }^{[1]}$.

\section{Political integration and reconstruction strategy of Chongqing rural society in the early years of establishment of the nation}

\section{Further reorganize management order of Chongqing rural area and enhance rural grass-roots system}

In the initial post-liberation period, Chongqing set up a temporary regime organization, i.e. People's Democratic Government Office. It was mainly responsible for taking over old regime of township government, establishing backbone peasant organization, maintaining and governing local safety. As social regime and political environment became stable, CCP and the government started to effectively annul traditional neighborhood administrative system in the practical operation process. In particular, in the early years of establishment of the nation, the tide of foreign democratic government construction was intensifying based on Instruction on Establishing County and Township People's Congress Conference. Chongqing local government shouldered the duty of solving harmful parameters in regime establishment process, effectively standardized management framework of primary-level organizations, really practiced the basic significance of political integration and reconstruction of rural society, consolidated and developed economy as well as achieved stably control of Chongqing.

\section{Effectively optimize and develop CCP and Chongqing rural political organization}

In the early years of establishment of the nation, CCP continuously promoted organization system construction level of rural area according to its development course, and combined the ability of Chongqing local government to directly bring peasants' union and the women's federation in rural structure into the discourse system. For local political pattern, this is an epoch-making change. But, in the early years of establishment of the nation, rural primary-level organizations in Chongqing also had some problems to be solved urgently, such as half-revolutionary ideas, rich peasant tendency and impure motivation of CCP members. Thus, under the general environment of national reorganization, Chongqing local government carried out political integration and reconstruction of rural society in order to further optimize peasants' ideology, improve ideological consciousness of rural CCP cadres and really eliminate harmful ideology and corruption phenomenon in CCP. This could not just effectively promote team purity, but also deepen CCP-people relationship, enhance fighting capacity of CCP and better facilitate development of Chongqing ${ }^{[2]}$. 


\section{Improve political enthusiasm and participation degree of Chongqing rural peasants}

As people's democratic system went deep and spread widely, Chongqing rural people also became the driving force of social construction and laid a solid foundation for rural work implementation. During improving people's enthusiasm, more flexible and diversified development mode was taken to conform to era development.

Improve political enthusiasm and participation degree of Chongqing rural peasants with the help of mobilization meeting

To fundamentally implement political integration and reconstruction course of Chongqing rural society, comprehensive control should be done from ideological level. Chongqing local government should comply with social demand, widely carry out peasant's congress and mass meeting to analyze current basic situation of China, put the policy of CCP into practice, regard elimination of adverse concern in ideology as the basic goal, organize and mobilize the masses to eliminate adverse effects of exploitation problem on the society as well as improve exchange and interaction effect through advanced and typical political rendering. Based on guiding peasants' ideology and emotion, timeliness value of mobilization meeting should be really exerted.

Improve political enthusiasm and participation degree of Chongqing rural peasants with the help of output increase competition activity

In the early years of establishment of the nation, China organized agricultural working conference. Each local government was required to establish patriotic production campaign in combination of respective development. In the development course of Chongqing, Chongqing also conformed to social development environment, set up production team and trained a large group of model workers and advanced workers. In addition, China specially issued Resolution on Cooperative Project in Agricultural Production for agricultural problem at the end of 1951. The resolution explicitly required local governments to actively carry out patriotic output increase action. Chongqing also kept boosting local agricultural production effect with the help of output increase competition activity. This is also an effective way to improve peasants' ideological level and political consciousness ${ }^{[3]}$.

Improve political enthusiasm and participation degree of Chongqing rural peasants with the help of newspaper and other advertising media

To fundamentally enhance project management mechanism, newspaper and broadcasting were mainly applies to advertise. Chongqing local government set corresponding control measures for specific problems, and enhanced propagandizing mechanism and management means to make sure communication media could combine local development status for mobilization activity, optimize communication speed and coverage range and upgrade medial transmission infection so as to really improve the force of medial transmission.

Improve political enthusiasm and participation degree of Chongqing rural peasants with the help of propaganda team

In the process of political integration and reconstruction of Chongqing rural peasants, the visual management measure used by local government was to fuse control measures and project propaganda. Besides, Chongqing also conformed to national development direction during operating relevant projects, and established propagandist system and reporter system within the range of the whole CCP. Management personnel should strengthen peasants' practical level while improving broadcast popularization rate and literacy mechanism. In particular, local management personnel should establish advanced model first to ensure overall management framework and level of local personnel. Only when timeliness of medical communication is guaranteed can high incentive function be ensured to construct more effective political integration and reconstruction and achieve optimal self-improvement of peasants. 


\section{Political function of political integration and reconstruction of Chongqing rural society in the early years of establishment of the nation}

\section{Break traditional and feudal power structure}

Effective utilization of political integration and reconstruction project of Chongqing rural society could improve overall project management timeliness, ensure optimization of control structure and really achieve upgrade of management level. Besides, this could not just achieve optimization and upgrade of Chongqing rural power structure, but also effectively maintain and supervise new order suitable foe social development as well as facilitate smooth completion of political integration and reconstruction project of Chongqing rural society. It was especially necessary to notice that in traditional rural society structure, regime, clan authority and theocracy presented interlaced power structure. They maintained the stability of rural political and economic structure, and expressed basic parameters of regime competition to certain degree. Thus, they played a great role. Implementation of political integration and reconstruction project of Chongqing rural society aimed to abolish traditional and feudal power structure and make sure new situation and new development trend could promote rural optimization and development, on the basis of conforming to era development trend.

\section{Reverse organization structure of Chongqing rural society}

Political integration and reconstruction project of Chongqing rural society aimed to gain more effective and benignant change and development for Chongqing rural area and make sure rural structure could achieve epochal character and politicalization. Firstly, the establishment of organization structure in rural area could make sure social environment and development mechanism obtain more benignant changes. In the development process, rural society systematism has obtained certain growth. On this basis, the organization structure established by local management personnel was based on CCP organization and people's regime, including specific operation framework and most rural social members. Thus, the establishment of political integration and reconstruction framework of Chongqing rural society aimed to improve management ability of rural society ${ }^{[4]}$. Secondly, through careful analysis of political development of Chongqing rural area, we can easily find the development trend of non-governmental social organization continuously develops. But, some non-governmental organizations were finally dissolved, because they failed to carry out optimal deconstructing of social development rend. Even some organizations lack necessary control mechanism in the operation process. Thus, CCP and Chongqing local government should fully deconstruct the responsibilities non-governmental organizations should undertaken and establish complete management measures and upgrade control mechanism so as to ensure normal operation of political integration and reconstruction of Chongqing rural society.

\section{Optimize basic quality of Chongqing rural peasants}

In traditional political structure, peasants' enthusiasm for participation in the administration and discussion of state affairs was not high due to the causes of their knowledge and social experience, and their small peasant consciousness was very serious. This was adverse to social progress and good development of agricultural project. Thus, in practical project operation process, Chongqing government should establish effective management measures for specific problems, actively encourage and guide peasants to participate in the administration and discussion of state affairs so as to really achieve optimization of overall political layout ${ }^{[5]}$. In addition, relevant project leaders should establish local management organization for specific problems, improve timeliness of CCP, youth group and the women's federation, guarantee stability and systematicness of grass-roots regime structure, drive political integration and reconstruction of Chongqing rural society and optimize peasants' management consciousness fundamentally so as to enhance their master awareness and facilitate further development of Chongqing rural area. 


\section{Upgrade Chongqing rural governance mode}

Under the guidance of CCP, it is required to integrate various political forces of Chongqing rural area and make sure all kinds of political relations can be effectively adjusted so as to upgrade the effect and level of political integration and reconstruction of Chongqing rural society and really establish the highly centralized and politicalized operation mode.

\section{Conclusion}

In one word, local government actively improved participation sense of all during political integration and reconstruction of Chongqing rural society. On this basis, political atmosphere of Chongqing rural area could develop, which laid a solid foundation for current rapid development of Chongqing.

\section{Acknowledgments}

This paper belongs to the project of Chongqing Social Science Planning Office (No.: 2015PY60), humanities \& social sciences project of Chongqing Board of Education Committee (No.: 15SKG191) and scientific research project of Chongqing University Of Science \& Technology (CH2016Z33).

\section{References}

[1] Peng Zhengde, Class mobilization and identification polymerization: a policy mobilization mode of CCP in rural society - investigation of Hunan Liling County. Journal of Social Science of Hunan Normal University, 2013,40(06):50-55.

[2] Zhao Xudong and Xin Yunxing, Discrete power and virtual authority: plight of "political integration” in Chinese rural area. Journal of Social Sciences, 2013,16(06):61-71.

[3] Lv Lianren, "CCP branch going to the countryside” and rural political integration in early years of establishment of the nation. Journal of Shandong University(Philosophy and Social Sciences), 2013,25(05):55-61.

[4] Zhao Quanmin and Xin Ping, "Different interest” in integration of rural society - focus on rural cooperation campaign in Jiangsu and Zhejiang in 1930s. Journal of East China Normal University (Philosophy and Social Sciences), 2013,35(01):34-41.

[5] Wu Shuxiong and Zhou Zhe, Research view and evaluation of rural integration and control factors beyond state system - based comparison of social functions of rural organizations under traditional gentry, early Nationalist Party and CCP. Journal of Hubei Administration Institute, 2014,17(02):13-17. 